\title{
Plasma concentrations of soluble CD40 ligand in smokers with acute myocardial infarction: a pilot study
}

\author{
Mehmet Kayrak • Ahmet Bacaksiz • Mehmet S. Ulgen • \\ Mehmet Akif Vatankulu $\cdot$ Kadriye Zengin · Selim S. Ayhan • \\ Mustafa Kemal Basaralı $\cdot$ Sadik Büyükbas $\cdot$ Aysel Kiyici
}

Received: 5 February 2009/ Accepted: 25 February 2010/Published online: 27 October 2010

(C) Springer 2010

\begin{abstract}
Coronary artery disease (CAD) is believed to be the single leading cause of death in both men and women in the world. Smoking is the most important risk factor for CAD. Smoking increases platelet aggregation and thrombus formation. CD40 ligand (CD40L) is a transmembrane glycoprotein derived from activated platelets. It participates in thrombus formation during the acute phase of acute myocardial infarction (MI). Elevation of CD40L identifies the patients who are at highest risk for cardiac events and who are likely to benefit from treatment with the glycoprotein IIb/IIIa (GPIIb/IIIa) receptor antagonists. The purpose of this study was to evaluate levels of CD40L in smokers with acute MI. Fifty-seven patients with acute MI were enrolled in this study. Thirty-one smokers were compared with 26 non-smokers. Soluble CD40L level in the plasma was determined by a standard enzyme-linked immunosorbent assay. Circulating levels of CD40L were higher in the smokers' group. Smokers with acute MI may have increased risk for thrombotic complications during acute MI, and optimal antiaggregant therapy should be administered.
\end{abstract}

Keywords Acute myocardial infarction . CD40 ligand $\cdot$ Smoking

M. Kayrak · A. Bacaksiz $(\bowtie) \cdot$ M. S. Ulgen

M. A. Vatankulu $\cdot$ K. Zengin - S. S. Ayhan .

M. K. Basaralı · S. Büyükbas

Department of Cardiology, Selcuk University Meram School

of Medicine, Akyokus Meram, 42090 Konya, Turkey

e-mail: ahmetbacaxiz@mynet.com

M. K. Basaralı · S. Büyükbas · A. Kiyici

Department of Biochemistry, Selcuk University Meram School of Medicine, Konya, Turkey

\section{Introduction}

Cigarette smoking is accepted as one of the major factors that increase the risk of coronary artery disease (CAD) and heart attacks. Smokers have a three to four times higher risk of developing a heart attack compared with nonsmokers [1]. A large number of young people suffering from myocardial infarction (MI) are smokers [2]. There are several ways in which tobacco can influence the cardiovascular system. Smoking accelerates atherosclerosis through damage to the endothelium and is associated with proinflammatory and prothrombotic responses. Post-mortem studies have provided evidence of accelerated atherogenesis in asymptomatic smokers [3]. Tobacco smoke also increases the blood coagulability contributing to MI. In vivo platelet activation occurs immediately after smoking a cigarette [4]. Smoking-induced platelet activation can be a significant contributory mechanism for acute coronary events in smokers.

CD40 and its ligand (CD40L) are glycoproteins from the tumor necrosis factor family [5]. Ligation of CD40 on various vascular cells contributes to the pathogenesis of atherosclerotic, thrombotic, and inflammatory processes $[6$, 7]. Soluble CD40L is shed from platelets upon platelet activation and triggers monocyte activation [8]. The pivotal role of platelet activation in atherothrombosis has made CD40L an interesting subject in the setting of cardiovascular disease and of acute MI. The rapid closure of the coronary artery by acutely formed arterial thrombi, which are composed of platelets, fibrin, and inflammatory cells, is the major cause of acute myocardial infarction [9]. Inflammatory markers like high-sensitivity C-reactive protein (CRP), human tumor necrosis factor $\alpha$, and interleukin 6 are elevated in acute coronary syndromes [10]. CD40L levels are also elevated in patients with acute MI 
[11]. In addition, several studies demonstrated that the circulating level of CD40L was related to a high thrombus burden in acute MI and long-term mortality [12-14]. Cigarette smokers also have upregulation of the CD40/ CD40L dyad [15]. However, there is no report about circulating levels of CD40L in smokers with acute MI. The aim of this study is to examine CD40L levels in smoker patients with acute MI versus non-smokers.

\section{Materials and methods}

\section{Patient population}

A total of 57 patients with ST-segment elevation AMI were enrolled in this study. Thirty-one smokers (group 1) were compared with 26 non-smokers (group 2). Smokers were defined as those currently smoking any type of tobacco in more than ten cigarettes per day and ex-smoker patients were excluded from the study. All patients provided informed consent for participating in the study. The study protocol was approved by the local ethics committee.

Exclusion criteria were diabetes mellitus, atrial fibrillation, renal or hepatic failure, significant valvular abnormalities, chronic obstructive pulmonary disease, active inflammatory or connective tissue diseases, malignancy, febrile disorders, cardiogenic shock patients requiring intraaortic balloon pump therapy, patients with a history of recent surgery or trauma within the preceding 2 months and those with acute MI onset $>24 \mathrm{~h}$, or age $\geq 85$ years. Patients were excluded if antiplatelet agents such as acetylsalicylic acid and clopidogrel had been used for any medical reason. Also, the patients that were given these agents and heparin during transfer to the hospital were excluded. None of the patients had a history of CAD, percutaneous coronary intervention (PCI), or coronary artery bypass graft surgery. Acute MI was defined as typical chest pain lasting for more than $30 \mathrm{~min}$ with ST-segment elevation $>1 \mathrm{~mm}$ in two or more consecutive precordial or extremity derivations.

\section{Study protocol}

Patients who were undergoing primary PCI were included in the study. All patients were treated with clopidogrel (loading $600 \mathrm{mg}$ PO before PCI and followed with $75 \mathrm{mg}$ daily), enoxaparin $(0.1 \mathrm{mg} / \mathrm{kg} \mathrm{SC})$, and a glycoprotein IIb/IIIa (GPIIb/IIIa) receptor antagonist (tirofiban; loading $20 \mu \mathrm{g} / \mathrm{kg}$ then $0.1520 \mu \mathrm{g} / \mathrm{kg} / \mathrm{min}$ infusion followed for $24 \mathrm{~h}$ ). In the emergency room during admission, PO $300 \mathrm{mg}$ acetylsalicylic acid was given. Blood samples were taken at hospital admission before the medical treatment with aspirin, clopidogrel, glycoprotein inhibitors, and PCI. Thrombolysis in the myocardial infarction (TIMI) flow [16] and TIMI frame count [17] of the infarct-related artery (IRA) were measured before and after the procedure. The severity of CAD was assessed by using the Gensini score [18].

Blood sampling and laboratory measurements

sCD40L levels were measured in plasma. Ethylenediaminetetraacetic acid (EDTA) was used as anticoagulant. All samples were stored at $-80^{\circ} \mathrm{C}$ until assayed. The concentration of soluble CD40L levels in plasma was determined by using a specific enzyme-linked immunosorbent assay (ELISA) kit (Bender MedSystems GmbH Vienna, Austria). Each serum sample was diluted 1:2 with sample diluent into the each well. The interassay coefficient of variation (CV) was $6.8 \%$, the intra-assay CV was $4.0 \%$, and the imprecision of the assay was $<10 \%$. All tests were done in duplicate. Blood samples for detecting the peak creatinine kinase-myocardial band (CK-MB) and troponin I values were taken every $8 \mathrm{~h}$ during the first 3 days after admission. The serum CK-MB levels were measured by an Olympus AU 600 autoanalyzer (Olympus Optical Co., Ltd., Schimatsu-Mishima, Japan). Troponin I was analyzed using a commercially available method (IMMULITE Troponin I, Diagnostic Products Corp., Los Angeles, CA). This is an immunometric method where antibodies raised against human cTnI bind to existing cTnI in the sample. C-reactive protein was measured by a nephelometry method.

\section{Statistical analysis}

The statistical analysis was performed with the help of the Statistical Package for Social Sciences (SPSS for Windows) software (version 11.0) (SPSS Inc., Chicago, IL). Differences in prevalence were tested with the nonparametric chi-square test. Unpaired $t$ tests were used for between-two-group comparisons. Also, the Mann-Whitney $U$ test was used for non-parametric comparison of two groups. A Spearmann correlation test was used to assess linear association. Variables were expressed as mean \pm standard deviation, and $p$ values $<0.05$ were considered statistically significant.

\section{Results}

In our study, the sample consisted of 57 patients. Patients were subdivided into two groups according to their smoking status. The circulating levels of soluble CD40L were higher in smokers than in non-smokers, but the difference was in the range of assay imprecision (6.14 vs. $5.07 \mathrm{ng} / \mathrm{ml}, p=0.01$ ) (Fig. 1). Smokers were 10 years younger than non-smokers $(p=0.001)$, and smoking was 


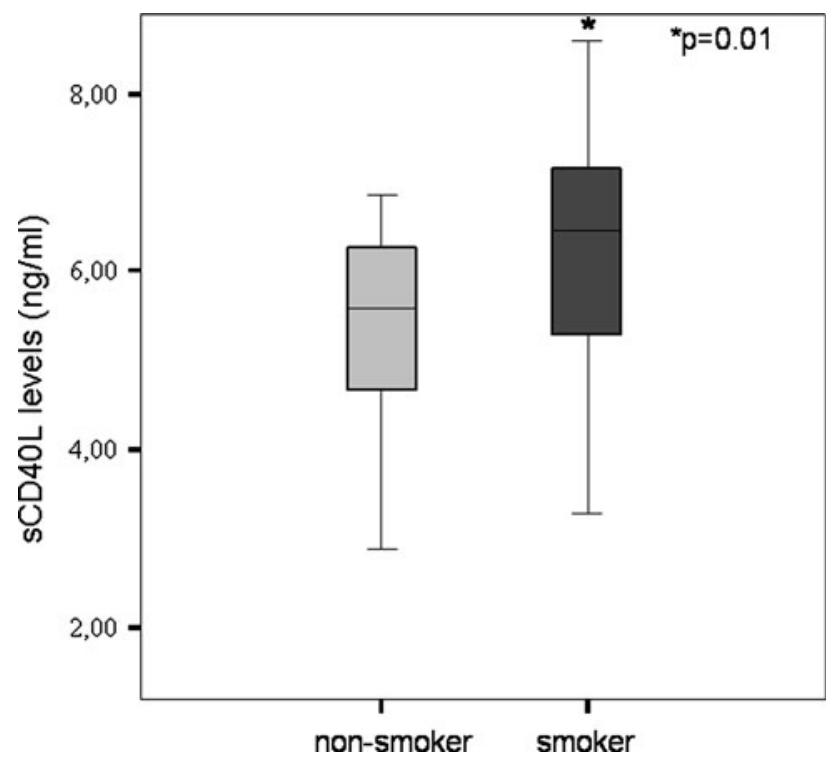

Fig. 1 CD40L levels of patients

Table 1 Baseline characteristics of patients in both groups

\begin{tabular}{lccl}
\hline & $\begin{array}{l}\text { Smokers } \\
(\text { group 1) } \\
(n=31)\end{array}$ & $\begin{array}{l}\text { Non-smokers } \\
\text { (group 2) } \\
(n=26)\end{array}$ & $p$ \\
\hline Age (years) & $53.0 \pm 8.8$ & $62.7 \pm 10.6$ & 0.001 \\
Male gender & 28 & 16 & 0.001 \\
Body mass index $\left(\mathrm{kg} / \mathrm{m}^{2}\right)$ & $25.8 \pm 3.1$ & $27.1 \pm 4.8$ & 0.3 \\
Hypertension $(\%)$ & 22 & 47 & 0.2 \\
LDL-cholesterol $(\mathrm{mg} / \mathrm{dl})$ & $124.5 \pm 32.7$ & $121.0 \pm 29.4$ & 0.7 \\
Creatinine $(\mathrm{mg} / \mathrm{dl})$ & $0.9 \pm 0.3$ & $0.9 \pm 0.2$ & 0.5 \\
WBC count $\left(\times 10^{3} / \mathrm{ml}\right)$ & $12.9 \pm 4.2$ & $11.8 \pm 4.2$ & 0.3 \\
Platelet counts $\left(\times 10^{4} / \mathrm{ml}\right)$ & $226.1 \pm 47.3$ & $220.0 \pm 44.2$ & 0.5 \\
Peak CK-MB $(\mathrm{IU} / \mathrm{l})$ & $217.9 \pm 129.7$ & $167.1 \pm 101.8$ & 0.2 \\
Peak troponin I $(\mathrm{ng} / \mathrm{ml})$ & $87.0 \pm 61.9$ & $73.3 \pm 57.3$ & 0.4 \\
Fibrinogen $(\mathrm{mg} / \mathrm{dl})$ & $329.5 \pm 123.1$ & $328.0 \pm 52.4$ & 0.9 \\
CD40L $(\mathrm{ng} / \mathrm{ml})$ & $6.1 \pm 1.5$ & $5.1 \pm 1.8$ & 0.01 \\
\hline
\end{tabular}

$W B C$ white blood cell, $L D L$ low density lipoprotein, $C K-M B$ creatine kinase myocardial band, $C D 40 L$ CD40 ligand

more common in males $(p=0.001)$ (Table 1). There were no significant differences between groups for other biochemical findings such as peak CK-MB, troponin I, creatinine and fibrinogen levels, WBC, and platelet counts.

The patients were divided into four groups to quartiles of CD40L level. Gensini scores of each CD40L quartile were similar ( $p=0.4$ ) (Fig. 2). Also, there was no correlation between the levels of CD40L and the Gensini score $(r=0.46, p=0.3)$.

Angiographic findings, such as infarct location (anterior, non-anterior), IRA, Gensini scores, and TIMI flow were similar in both groups (Table 2). Also, times from

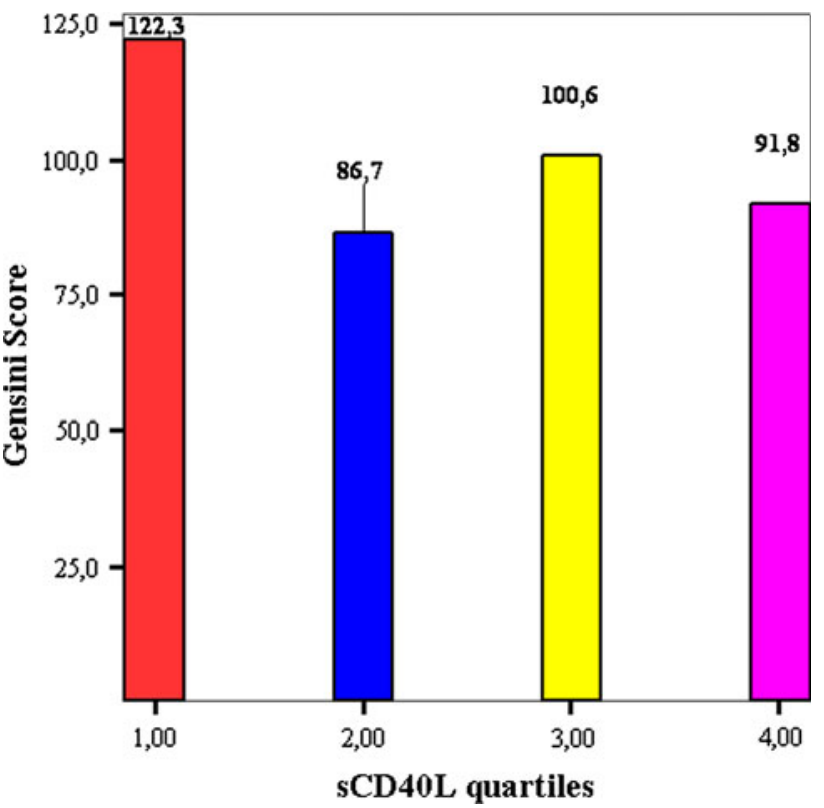

Fig. 2 Association between CD40L levels and Gensini scores

symptom onset to reperfusion therapy were similar. The TIMI frame count after the reperfusion procedure was similar in each group $(p=0.16)$.

The plasma levels of sCD40L were analyzed for correlation among demographic, laboratory, and angiographic parameters (Table 3). There was no correlation between plasma sCD40L levels and other parameters such as age, Gensini score, peak CK-MB, and troponin levels, etc.

\section{Discussion}

In this study, sCD40L levels were evaluated in patients undergoing primary PCI for acute MI. The circulating levels of SCD40L were elevated in both smokers and nonsmokers during the early phase of acute MI. In spite of higher CD40L levels, the post-procedural TIMI flow was similar in each group. GPIIb/IIIa receptor antagonist administration after PCI to all patients could be a possible explanation for improved coronary flow inspite of high sCD40L levels.

Smoking has been identified as a major risk factor for CAD. A complex relationship exists between cigarette smoking, haemostatic factors, and cardiovascular disease. Celermajer et al. [19] found a marked reduction in both flow-mediated, endothelium-dependent and nitroglycerininduced, endothelium-independent vasodilatation of the forearm arteries in long-term smokers. After disruption of the endothelial layer, blood coagulation starts by platelet activation and interaction of activated platelets. Platelets also increased their activation as a response to cigarette 
Table 2 Angiographic characteristics

\begin{tabular}{llll}
\hline & Smoker (group 1) $(n=31)$ & Non-smoker $($ group 2) $(n=26)$ & $p$ \\
\hline Anterior wall MI & 24 & 23 & 0.17 \\
Infarct-releated artery (LAD/Cx/RCA) & $24 / 3 / 4$ & $23 / 0 / 3$ & 0.25 \\
Gensini score & 76 (IQR: 48) & 108 (IQR: 97.5$)$ & 0.20 \\
Time from symptom onset to reperfusion therapy (h) & 3.5 (IQR: 2) & 4.5 (IQR: 2.5$)$ & 0.28 \\
Pre-PCI TIMI flow & 0 (IQR: 0.5) & 0 (IQR: 0.25$)$ & 3 (IQR: 0.5$)$ \\
Post-PCI TIMI flow & 3 (IQR: 1$)$ & 22.0 (IQR: 11.5$)$ & 0.67 \\
TIMI frame count after the procedure & 16.5 (IQR: 8.75$)$ & 0.14 \\
\hline
\end{tabular}

$I Q R$ interquartile range, $M I$ myocardial infarction, $L A D$ left anterior descending artery, $C x$ circumfrex coronary artery, $R C A$ right coronary artery, $P C I$ percutaneous coronary intervention, TIMI thrombolysis in myocardial infarction

Table 3 Correlation between sCD40L levels and demographic features, laboratory findings, and angiographic characteristics

\begin{tabular}{lcc}
\hline Variables & \multicolumn{2}{l}{ sCD40L } \\
\cline { 2 - 3 } & $\begin{array}{l}\text { Correlation } \\
\text { coefficient }(r)\end{array}$ & $p$ \\
\hline Age & $0.03^{\mathrm{a}}$ & 0.79 \\
BMI & $0.10^{\mathrm{a}}$ & 0.47 \\
Creatinine & $0.06^{\mathrm{a}}$ & 0.60 \\
WBC & $-0.03^{\mathrm{a}}$ & 0.79 \\
Peak CK-MB & $0.11^{\mathrm{a}}$ & 0.36 \\
Peak troponin I & $0.14^{\mathrm{a}}$ & 0.30 \\
Time from symptom onset & $0.18^{\mathrm{b}}$ & 0.17 \\
to reperfusion therapy & & \\
Pre-PCI TMI frame count & $-0.06^{\mathrm{b}}$ & 0.64 \\
Post-PCI TIMI frame count & $-0.07^{\mathrm{b}}$ & 0.61 \\
Gensini score & $-0.15^{\mathrm{b}}$ & 0.28 \\
\hline
\end{tabular}

$B M I$ body mass index, $W B C$ white blood cell, $C K-M B$ creatine kinase myocardial band, $P C I$ percutaneous coronary intervention, TIMI thrombolysis in myocardial infarction

${ }^{\text {a }}$ Correlation coefficient was obtained with Pearson correlation analysis

b Correlation coefficient was obtained with Spearman's correlation analysis

smoke. Soluble CD40L is released from activated platelets. Harding et al. [15] demonstrated that the expression of CD40L on platelets and platelet-monocyte aggregates significantly increased in healthy smokers compared to non-smokers.

There have been contradictory results about the relation between SCD40L levels and atherosclerosis risk factors. In a large multiethnic population-based study, no association was observed between quartiles of sCD40L and age, sex, race, body mass index, diabetes, cholesterol levels, and CRP [20]. In the Framingham Study participants, as opposed to never smokers, those with acute cigarette smoke exposure had significantly lower concentrations of plasma CD40L [21]. In this study, patients in the smoking group were younger and more likely to be male, but age and sex did not affect circulating CD40L levels.

There are limited data about the levels of CD40L during acute coronary syndromes (ACS). Aukrust et al. [22] showed that patients with stable and unstable angina had elevated levels of CD40L compared with controls; particularly high levels occurred in patients with unstable disease. In addition, Heeschen et al. [11] demonstrated that the levels of CD40L were significantly higher in patients with ACS (62\% of the patients with ST-segment elevation MI) than in patients with stable angina and patients without heart disease. Except these reports, sufficient data are not available concerning the sCD40L levels in acute ST segment elevation MI. Youssef et al. [14] recently studied the relation between the circulating level of $\mathrm{SCD} 40 \mathrm{~L}$ and thrombus burden in the infarct-related artery. In the acute phase of MI, sCD40L levels were significantly higher in the high thrombus formation group compared to the low thrombus formation group. In the subgroup analysis of the OPUS-TIMI 16 trial, Varo et al. [23] found that elevated plasma levels of sCD40L $(>0.52 \mathrm{ng} / \mathrm{ml})$ identify the patients with acute coronary syndromes at heightened risk of death and recurrent MI independent of troponin-I and CRP. The authors noted that the elevated levels of CD40L not only play a central role in the pathogenesis of atherosclerosis and CAD, but also help to identify the patients at high risk for ischemic events during acute coronary syndromes. The predictive value of serum sCD40L levels was investigated in patients with acute coronary syndromes who were enrolled in the CAPTURE study [11]. The sCD40L levels were elevated (above $5.0 \mu \mathrm{g} / \mathrm{l}$ ) in 221 patients $(40.6 \%)$. Elevated SCD40L levels were associated with death and non-fatal MI during 6 months of follow-up. The increased risk in patients with elevated SCD40L levels was significantly reduced by treatment with abciximab. Similarly, smokers had higher sCD40L levels in this study ( 6.14 vs. $5.07 \mathrm{ng} / \mathrm{ml}$; the difference was in the range of assay imprecision). This could be explained with more thrombogenic, less atherogenic composition of the infarct 
lesion in smokers [24]. Smoking enhances platelet aggregation and then thrombus formation [25]. Soluble CD40L released from platelets upon activation indicates the hypercoagulable state promoting vascular thrombosis in active smokers.

Two studies were found in the literature search $[26,27]$ in which CD40L failed to predict the prognosis after acute MI. Tan et al. [26] reported that elevated levels of CD40L had no prognostic value for patients with ST segment elevation MI in 2 years of follow-up. The result of this study is controversial because for cardiovascular morbidity, including re-MI, rehospitalization for acute coronary syndromes were not evaluated during the follow-up period. Secondly, Morrow et al. [27] detected that SCD40L was not associated with a risk of non-fatal recurrent ischemic events in patients with non-ST elevation acute coronary syndromes. The authors have discussed that the uniform treatment of patients in this study with a platelet GPIIb/IIIa receptor antagonist had an impact on the strength of the relationship. This argument is supported by the results of the present study.

Elevation of sCD40L identifies the patients who are at highest risk for cardiac events [11]. Recently, many studies have shown that GPIIb/IIIa receptor antagonists are capable of inhibiting the release of sCD40L in a dose-dependent manner [27-29]. We hypothesized that smokers with acute ST elevation MI who undergo primary angioplasty could benefit from GPIIb/IIIa inhibitor use to a greater extent than non-smokers, but there are conflicting data about the benefits of glycoprotein IIb/IIIa (GPIIb/IIIa) receptor antagonist treatment in smoking patients with acute MI and elevated sCD40L levels $[11,30,31]$. In the CAPTURE study including patients with acute coronary syndromes, the increased risk in both smoker and non-smoker patients with elevated SCD40L levels was significantly reduced by treatment with abciximab [11]. Hasdai et al. [30] evaluated the effect of eptifibatide, a GPIIb/IIIa receptor antagonist, in smokers with acute non-ST elevation MI in the PURSUIT trial. Eptifibatide did not result in more improvement in smokers' outcomes compared with nonsmokers. Weisz et al. [31] examined the impact of smoking on patients undergoing primary PCI for AMI in the CADILLAC trial. Abciximab was not associated with better outcome in smokers. Taken together, a greater benefit of GPIIb/IIIa receptor blocker therapy in smoking acute MI patients compared with non-smokers is still controversial and needs to be addressed in larger studies.

In one study, Lee et al. [32] examined the relation between higher CD40L levels and Gensini score in patients with stable angina requiring interventional treatment. Elevated $\mathrm{SCD} 40 \mathrm{~L}$ levels and $\mathrm{CAD}$ severity calculated with Gensini scores were more common in patients with metabolic syndrome. We did not find any difference among the
sCD40L quartiles for the Gensini score, and there was no correlation between the sCD40L levels and the Gensini score. The association between elevated SCD40L levels and CAD severity has not been mentioned before in acute MI. This score is accepted as a marker of severity of CAD in stable patients. Severity of the Gensini scores is substantially influenced by the degree and location of obstruction. Gensini scores of stable patients may be suddenly increased in acute MI because total occlusion due to thrombus formation was frequently seen in angiographic records of patient with acute MI. In addition, it is well known that SCD40L plays a pivotal role in thrombus formation, but the relationship between sCD40L levels and localization of the thrombotic lesion site is not clear. In summary, we did not detect any association between sCD40L levels and Gensini score. Despite increased sCD40L levels in smokers, Gensini scores were similar in both groups.

\section{Study limitations}

This study is a pilot study raising a hypothesis that must be confirmed in larger studies. The main limitation of this study is the small sample size. Because of this limitation, multivariate regression analysis was not performed to detect the independent predictors of the sCD40L level, and also an independent association between smoking status and plasma sCD40L level was not interpreted. Results could be strengthened with additional evidence confirming activation of the SCD40L pathway. Another limitation of the study is the lack of healthy subjects as a control group. The results of this study cannot be generalized to late-term revascularized patients. Additionally, this is a cross-sectional study, and therefore, the importance of the results should be assessed by clinic follow-up studies. We studied the patients undergoing primary PCI, and all patients received tirofiban, enoxaparine, clopidogrel, and acetylsalicylic acid. Hence, the present study does not answer the question of whether smokers with acute MI were at a disadvantage with the therapy not including GPIIb/IIIa receptor antagonists.

\section{Conclusion}

Despite these limitations, this study demonstrated that circulating levels of sCD40L are increased in smokers during the early phase of acute MI. Therefore, smokers with acute MI may have an increased risk of thrombotic complications during acute MI. Optimal antiaggregant therapy including GPIIb/IIIa receptor antagonists should be administered to patients smoking cigarettes during the acute MI setting. 
Acknowledgments The authors would like to express their special thanks to the staff at the Department of Cardiology, Faculty of Medicine Hospital, Selcuk University, Konya, Turkey, for their kind cooperation when conducting this study.

\section{References}

1. Doyle JT, Dawber TR, Kannel WB, Heslin AS, Kahn HA (1962) Cigarette smoking and coronary heart disease. N Engl J Med 266:796-801

2. Mohanty D, Shetty S, Anil CR, Pathare A, Ghosh K, Yeolekar ME (1998) Factor V Leiden gene mutation in young Indian patients with myocardial infarction. Curr Sci 74:1078-1079

3. Fitzgerald GA, Jates JA, Nowak J (1988) Cigarette smoking and hemostatic function. Am Heart J 115:267-271

4. Nair S, Kulkarni S, Camoens HMT, Ghosh K, Mohanty D (2001) Changes in platelet receptors after smoking-a flow cytometric study. Platelets 12:20-26

5. Freedman JE (2003) CD40-CD40L and platelet function: beyond hemostasis. Circ Res 92:944-946

6. Henn V, Slupsky JR, Grafe M, Anagnostopoulos I, Forster R, Muller-Berghaus G (1998) CD40 ligand on activated platelets triggers an inflammatory reaction of endothelial cells. Nature 391:591-594

7. Mach F, Schonbeck U, Sukhova GK, Atkinson E, Libby P (1998) Reduction of atherosclerosis in mice by inhibition of CD40 signalling. Nature 394:200-203

8. Santilli F, Basili S, Ferroni P, Davì G (2007) CD40/CD40L system and vascular disease. Intern Emerg Med 2:256-268

9. Horii $M$, Uemura $S$, Uemura $M$, Matsumoto $M$, Ishizashi $H$, Imagawa K, Iwama H, Takeda Y, Kawata H, Nakajima T, Fujimura Y, Saito Y (2008) Acute myocardial infarction as a systemic prothrombotic response condition evidenced by increased von Willebrand factor over ADAMTS13 activity in coronary and systemic circulation. Heart Vessels 23:301-307

10. Ozer N, Tangurek B, Firat F, Ozer S, Tartan Z, Ozturk R, Ozay B, Ciloglu F, Yilmaz H, Cam N (2008) Effects of drug-eluting stents on systemic inflammatory response in patients with unstable angina pectoris undergoing percutaneous coronary intervention. Heart Vessels 23:75-82

11. Heeschen C, Dimmeler S, Hamm CW, van den Brand MJ, Boersma E, Zeiher AM, Simoons ML (2003) Soluble CD40L ligand in acute coronary syndromes. N Engl J Med 348:1104-1111

12. André P, Prasad KS, Denis CV, He M, Papalia JM, Hynes RO, Phillips DR, Wagner DD (2002) CD40L stabilizes arterial thrombi by a b3 integrin-dependent mechanism. Nat Med 8:247-252

13. André P, Nannizzi-Alaimo L, Prasad SK, Phillips DR (2002) Platelet-derived CD40L: the switch-hitting player of cardiovascular disease. Circulation 106:896-899

14. Youssef AA, Chang LT, Sheu JJ, Lee FY, Chua S, Yeh KH, Yang $\mathrm{CH}$, Wu CJ, Yip HK (2007) Association between circulating level of CD40 ligand and angiographic morphologic features indicating high-burden thrombus formation in patients with acute myocardial infarction undergoing primary coronary intervention. Circ J 71:1857-1861

15. Harding SA, Sarma J, Josephs DH, Cruden NL, Din JN, Twomey PJ, Fox KA, Newby DE (2004) Upregulation of the CD40/CD40 ligand dyad and platelet-monocyte aggregation in cigarette smokers. Circulation 109:1926-1929

16. The TIMI Study Group (1985) The Thrombolysis in Myocardial Infarction (TIMI) trial. N Engl J Med 312:932-936

17. Gibson CM, Cannon CP, Daley WL, Dodge JT Jr, Alexander B Jr, Marble SJ, McCabe CH, Raymond L, Fortin T, Poole WK,
Braunwald E (1996) TIMI frame count: a quantitative method of assessing coronary artery flow. Circulation 93:879-888

18. Gensini GG (1983) A more meaningful scoring system for determining the severity of coronary heart disease. Am J Cardiol 51:606

19. Celermajer DS, Sorensen KE, Georgapoulos D, Bull C, Thomas O, Robinson J, Deanfield J (1993) Cigarette smoking is associated with dose related and potentially reversible impairment of endothelium dependent dilatation in healthy young adults. Circulation 88(Suppl I):I-2149-I-2155

20. de Lemos JA, Zirlik A, Schönbeck U, Varo N, Murphy SA, Khera A, McGuire DK, Stanek G, Lo HS, Nuzzo R, Morrow DA, Peshock R, Libby P (2005) Association between soluble CD40 ligand, atherosclerosis risk factors and subclinical atherosclerosis. Arterioscler Thromb Vasc Biol 25:2192-2196

21. Levitzky YS, Guo CY, Rong J, Larson MG, Walter RE, Keaney JF Jr, Sutherland PA, Vasan A, Lipinska I, Evans JC, Benjamin EJ (2008) Relation of smoking status to a panel of inflammatory markers: the Framingham offspring. Atherosclerosis 201:217-224

22. Aukrust P, Müller F, Ueland T, Berget T, Aaser E, Brunsvig A, Solum NO, Forfang K, Frøland SS, Gullestad L (1999) Enhanced levels of soluble and membrane-bound CD40 Ligand in patients with unstable angina. Possible reflection of $\mathrm{T}$ lymphocyte and platelet involvement in the pathogenesis of acute coronary syndromes. Circulation 100:614-620

23. Varo N, de Lemos JA, Libby P, Morrow DA, Murphy SA, Nuzzo R, Gibson CM, Cannon CP, Braunwald E, Schönbeck U (2003) Soluble CD40L: risk prediction after acute coronary syndromes. Circulation 108:1049-1052

24. Ishihara M, Sato H, Tateishi H, Kawagoe T, Shimatani Y, Kurisu S, Sakai K, Ueda K (1997) Clinical implications of cigarette smoking in acute myocardial infarction: acute angiographic findings and long-term prognosis. Am Heart J 134:955-960

25. Leone A (2007) Smoking, haemostatic factors, and cardiovascular risk. Curr Pharm Des 13:1661-1667

26. Tan J, Hua Q, Gao J, Fan ZX (2008) Clinical implications of elevated serum interleukin-6, soluble CD40 ligand, metalloproteinase-9, and tissue inhibitor of metalloproteinase- 1 in patients with acute ST-segment elevation myocardial infarction. Clin Cardiol 31:413-418

27. Morrow DA, Sabatine MS, Brennan M, de Lemos JA, Murphy SA, Ruff CT, Rifai N, Cannon CP, Hazen SL (2008) Concurrent evaluation of novel cardiac biomarkers in acute coronary syndrome: myeloperoxidase and soluble CD40 ligand and the risk of recurrent ischaemic events in TACTICS-TIMI 18. Eur Heart J 29:1096-1103

28. Nannizzi-Alaimo L, Alves VL, Phillips DR (2003) Inhibitory effects of glycoprotein IIb/IIIa antagonists and aspirin on the release of soluble CD40 ligand during platelet stimulation. Circulation 107:1123-1128

29. Furman MI, Krueger LA, Linden MD, Barnard MR, Frelinger AL 3rd, Michelson AD (2004) Release of soluble CD40L from platelets is regulated by glycoprotein IIb/IIIa and actin polymerization. J Am Coll Cardiol 43:2319-2325

30. Hasdai D, Holmes DR Jr, Criger DA, Topol EJ, Califf RM, Wilcox RG, Paolasso E, Simoons M, Deckers J, Harrington RA (2000) Cigarette smoking status and outcome among patients with acute coronary syndromes without persistent ST-segment elevation: effect of inhibition of platelet glycoprotein IIb/IIIa with eptifibatide. The PURSUIT trial investigators. Am Heart J 139:454-460

31. Weisz G, Cox DA, Garcia E, Tcheng JE, Griffin JJ, Guagliumi G, Stuckey TD, Rutherford BD, Mehran R, Aymong E, Lansky A, Grines CL, Stone GW (2005) Impact of smoking status on outcomes of primary coronary intervention for acute myocardial 
infarction-the smoker's paradox revisited. Am Heart J 150: 358-364

32. Lee WL, Lee WJ, Chen YT, Liu TJ, Liang KW, Ting CT, Sheu WHH (2006) The presence of metabolic syndrome is independently associated with elevated serum CD40 ligand and disease severity in patients with symptomatic coronary artery disease. Metabolism 55:1029-1034 